virtually complete. Unconjugated steroids were found to represent only a small part of the total excretion, but Bailey et al. (1961, 1963) observed that the amount of free prednisolone excreted was proportional to the dose given, and that excretion of free prednisolone was almost complete in eight hours (personal communication). With doses of up to $100 \mathrm{mg}$. approximately $10 \%$ of the dose was excreted as free prednisolone, and the results in our controls, which were obtained with basically the same method, are in agreement with this.

The results in the patients with ulcerative colitis show that prednisolone is absorbed to a variable extent from the rectum, but in relatively small amounts. The average excretion of free prednisolone in four patients was approximately one-sixth of that found after oral administration. The variation was much greater than in the subjects who took prednisolone orally, possibly owing to variations in the time of retention, although all the patients succeeded in retaining the enemas for at least two hours, which is thought to be the minimum time necessary therapeutically. In only one of the eight 24 -hour periods was the urine prednisolone more than $3 \%$ of the dose given, and the highest value of $4 \%$ is about one-third of the mean found after the oral dosage. Even this is less than the equivalent of $7 \mathrm{mg}$. of oral prednisolone for most of the therapeutic period, and is very unlikely to account for the efficacy of rectal treatment or to cause pituitary or adrenal cortical suppression.

We cannot say whether the suppression which follows treatment with betamethasone enemata is due to the more powerful suppressing effect of betamethasone or whether the rectal mucosa absorbs betamethasone to a greater extent.

\section{Summary}

An investigation was made to determine whether any rectal absorption of prednisolone-21-phosphate occurs after giving the therapeutic enemas. Direct estimations were made of the urinary excretion of prednisolone and metabolites after giving prednisolone either orally or rectally. in nine subjects. The results after correction for incomplete recovery were compared and an estimation of the amount of prednisolone absorbed following intrarectal administration of the therapeutic enemas of prednisolone was made. The results show that less than the equivalent of a daily oral dose of $7 \mathrm{mg}$. of prednisolone is absorbed from the rectum when a daily therapeutic enema regime of $40 \mathrm{mg}$. of prednisolone-21-phosphate is given to ulcerative colitis patients. This should not cause adrenal cortical or pituitary suppression, nor could it account for the therapeutic efficacy of the intrarectal method of treatment.

We are grateful to the Birmingham Regional Hospital Board for the grant which made this work possible, and to the physicians of the Royal Hospital for allowing us to investigate the patients under their care.

\section{REFERENCES}

Bailey, E., Murphy, D., and West, H. F. (1961). Lancet, 2, 347. Bus - (1963). Arch. Dis. Childh., 38, 71. Bush, I. E. (1961). The Chromatography of Steroids. Pergamon Press, Matts, S. G. F., Wharton, B. A., Kelleher, J., and Walters, G. (1963)
Brit. med.

Sandberg, A. A., and Slaunwhite, W. R. (1957). 7. chin. Endocr., 17, 1040 .

Umberger, E. J. (1955). Analyt. Chem., 27, 768.

Vermeulen, A. (1959). F. Endocr., 18, 278 .

\title{
Pain Following E.C.T. Modified by Muscle Relaxants
}

\author{
R. DEVINE,* м.B., CH.B.; K. J. NEWTON, $†$ м.в., CH.B., D.P.M. ; F. G. SPEAR, $\ddagger$ м.в., CH.в., D.P.M.
}

It has been suggested (Tewfik, 1963) that pain related to the administration of suxamethonium chloride is comparatively uncommon after E.C.T. Pain of this type occurring after operations in women where this drug has been used was first noted by Currie (1953). Later investigations report an incidence which varies from $20 \%$ (Hegarty, 1956) to around $70 \%$ (Churchill-Davidson, 1954 ; Morris and Dunn, 1957). It seems to be generally agreed that the symptom is commonest in out-patients and can be prevented to a certain extent by postoperative bed-rest (Burtles and Tunstall, 1961). These findings in patients who have had operations or been investigated under anaesthesia cast doubt on the clinical impression of a lowered incidence of muscular pain after suxamethonium chloride and E.C.T., as those receiving this treatment are of ten out-patients and nearly always ambulant. In view of this a prospective study of the incidence of pain in patients receiving suxamethonium chloride and E.C.T. has been carried out.

Patients undergoing electroplexy sometimes complain of headache after the treatment. All the clinical reports of pain after administration of suxamethonium chloride agree that the pain is muscular, occurring in the back, chest, and limbs. We can therefore examine the incidence of both headache and muscular pains and their relation to treatment.

* Temporary Lecturer in Psychiatry, University of Sheffield.

+ Senior House Officer, United Sheffield Hospitals.

Senior House Onchiatry, University of Sheffield.
All patients starting a course of E.C.T. between 17 September and 24 December 1963 were interviewed during the study. Four out-patients were omitted because the erratic nature of their attendance prevented adequate assessment. The results are derived from the findings on 47 patients $(22$ male and 25 female) aged 16-74 years (mean 41.62 years) who underwent a total of 259 anaesthetics and treatments.

Treatment was carried out twice a week and patients were interviewed on treatment days, before the arrival of the anaesthetist. They were told that the object of the investigations was to examine the possible side-effects of E.C.T. Attention was primarily directed to subjective loss of memory, and information about physical symptoms, including pain, was sought secondarily. Nevertheless, when pain was not reported spontaneously direct questions were asked, put in the form which " expects the answer no." The site, characteristics, and relation to treatment of the various pains reported were recorded. Muscular pain occurring after treatment in the neck, trunk, and limbs was regarded as related to the administration of suxamethonium chloride. Headache is considered separately. The presence of other pain related to the patient's illness was noted.

An Ectron machine was used to administer E.C.T. and the stimulus was given alternately by an "instant" or a "glisssando" method, as it was thought possible that the 
reduced initial muscular contraction induced by the latter method would modify the incidence of pain. Records were kept of the extent to which the convulsion was modified. The interviewer was unaware of the results of this part of the investigation.

\section{Results}

Thirteen out of 47 patients reported pain attributable to suxamethonium chloride administration after at least one of their treatments. Twenty-seven patients reported headache after at least one treatment. Of the total of 259 treatments, 18 gave rise to muscular pains, 58 to headaches, and 4 to both. The relation of pain to the sequence of treatments is shown in Table I. Although it appears that muscular pain occurs most commonly after the first two treatments, this possibility cannot be statistically examined post hoc. We examined the possibility that the first treatment might be most important, comparing the incidence of pain on first treatment only with the incidence for all subsequent treatments combined, using McNemar's test (quoted by Maxwell, 1961). This test examines the significance of changes in the presence or absence of a variable when the same population is examined on two occasions. Its use takes into account the fact that the populations are not independent by examining only those cases in which change has occurred. There was no significant difference for muscular pains, but there was a significantly higher incidence of headache occurring for the first time in later treatments (Tables II and III).

TABLE I.-Incidence of Pain in Treatment Sequence

\begin{tabular}{|c|c|c|c|c|c|c|c|c|c|c|}
\hline & & & & \multicolumn{6}{|c|}{ Treatment } & \multirow{2}{*}{ Total } \\
\hline & & & & 1st & 2nd & $3 \mathrm{rd}$ & 4th & 5 th & $6 \mathrm{th}+$ & \\
\hline $\begin{array}{l}\text { Headache o } \\
\text { Muscular p } \\
\text { Both } \\
\text { Neither }\end{array}$ & $\begin{array}{c}\text { only } \\
\text { pain } \\
\ldots \\
.\end{array}$ & $\begin{array}{l}1 y \\
\cdots \\
\cdots\end{array}$ & $\begin{array}{l}\cdots \\
\cdots \\
\cdots\end{array}$ & $\begin{array}{r}8 \\
8 \\
2 \\
29\end{array}$ & $\begin{array}{r}12 \\
5 \\
1 \\
29\end{array}$ & $\begin{array}{r}13 \\
0 \\
0 \\
33\end{array}$ & $\begin{array}{r}10 \\
0 \\
0 \\
31\end{array}$ & $\begin{array}{r}9 \\
1 \\
1 \\
24\end{array}$ & $\begin{array}{r}6 \\
4 \\
0 \\
33\end{array}$ & $\begin{array}{r}58 \\
18 \\
4 \\
179\end{array}$ \\
\hline Total & . & .. & .. & 47 & 47 & 46 & 41 & 35 & 43 & 259 \\
\hline
\end{tabular}

TABLE II.-Patients Complaining of Muscular Pain on First and Subsequent Treatments

No. of

5.

Muscular pain after 1st treatment and after one or more later treatments

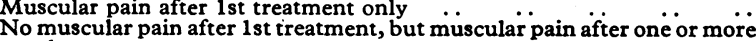

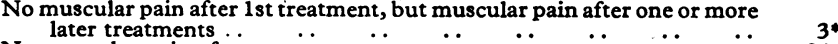

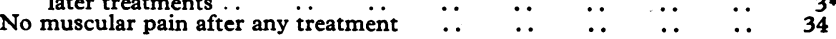

* It is these entries which are used in the computation of $\chi^{2}$ in McNemar's test.

TABLE III.-Patients Complaining of Headache on First and Subsequent Treatments

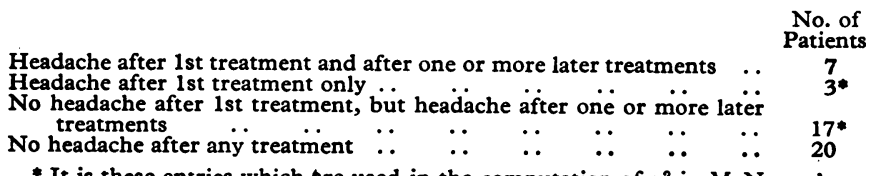

When the incidence in patients as opposed to that in separate treatments is considered we find that 4 out of 47 patients had muscular pain only, 18 had headache only, while 9 had pains of both types at some time or other. Nine of the patients with muscular pains and 17 of those with headache were females. Twenty patients previously had pain related to their psychiatric illness ; six of these developed muscular pain and 10 developed headache. None of these relations is statistically significant, nor was there any relation between muscular pain and degree of modification-13 pains occurring when shocks were well modified-or mode of administration, when 12 pains occurred after instant E.C.T.

Finally, the incidence of muscular pain in this series was compared with that in the other reports available to us. Details of this comparison are presented in Table IV. There is no significant difference between the overall incidence of pain in patients in this series and the overall incidence in other reports. A better comparison might be between the incidence of muscular pain arising after the first treatment in this series and the overall incidence in other series, as our patients differ in that they are having E.C.T. and therefore have several anaesthetics each. When this comparison is made a significantly lower incidence of pain is found in patients receiving E.C.T. $\left(\chi^{2}=5.33, \mathrm{df}=1\right.$, $\mathrm{P}<0.025$ ). Further, when a comparison is made between this series and the two series which are more closely comparable with it-that is, the out-patient series of Churchill-Davidson (1954) and Foster (1960)-the incidence is significantly lower in the patients receiving E.C.T. $\left(\chi^{2}=16.36, \mathrm{df}=2, \mathrm{P}<0.001\right)$. If the incidence is related to treatments a very highly significant $\chi^{2}$ can be computed, in relation either to comparable series or to all series. Although such a computation may not be strictly valid because of a possible lack of independence in the data, the effects of correlated data in this series will be relatively slight, so a significance level of $\mathrm{P}<0.0005$ can probably be taken as indicating a genuinely lower incidence of muscular pain in this series.

\section{Discussion}

Any discussion of pain problems in psychiatric patients is fraught with difficulty. The relationship of complaint of pain to bodily disorder may be exceedingly complex. However, it seems probable that in this investigation these difficulties arise mainly in relation to complaints of headache. Here the increasing incidence with later treatments may be connected with psychological factors. Among these may be, first, that the patients come to expect this symptom, perhaps from discussion among themselves, and so increasingly report minor discomfort in the head. The interviewer in this investigation formed the subjective impression that such a process was going on, at least to some extent. Second, the disturbance of memory consequent upon E.C.T. may cause an apprehension of possible damage to the brain, and headache may arise through a mechanism of the type described by Szasz (1957). It should be possible to demonstrate such an association, but the data in this experiment are invalid for the purpose, as the patients' attention was deliberately directed to their memory disturbance.

Engel (1959) has suggested that some patients may be " painprone." Such patients might be expected to develop pain of one type or another after E.C.T. However, it is probable that these patients would also have other pains related to their illness, so that a relationship could be demonstrated between the presence of pain as a psychiatric symptom and the development of new pains after E.C.T. This has not occurred in our patients.

The muscular pains reported by patients in this investigation can reasonably be attributed to the effects of suxamethonium

TABLE IV.-Incidence of Muscular Pain in Present Series and in Other Reported Series

\begin{tabular}{|c|c|c|c|c|c|c|c|c|c|c|c|c|}
\hline & \multirow{2}{*}{\multicolumn{2}{|c|}{ Present Series }} & \multicolumn{10}{|c|}{ No. of Patients } \\
\hline & & & \multirow{2}{*}{$\begin{array}{l}\text { Present } \\
\text { Series }\end{array}$} & \multirow{2}{*}{$\begin{array}{c}\text { Burtles } \\
\text { and } \\
\text { Tunstall } \\
\text { (1961) }\end{array}$} & \multicolumn{2}{|c|}{$\begin{array}{c}\text { Churchill-Davidson } \\
(1954)\end{array}$} & \multicolumn{2}{|c|}{$\begin{array}{l}\text { Foster } \\
(1960)\end{array}$} & \multirow{2}{*}{$\begin{array}{l}\text { Hegarty } \\
(1956)\end{array}$} & \multirow{2}{*}{$\begin{array}{l}\text { Leather- } \\
\text { dale et al. } \\
\text { (1959) }\end{array}$} & \multirow{2}{*}{$\begin{array}{l}\text { Morris } \\
\text { and } \\
\text { Dunn } \\
(1957)\end{array}$} & \multirow{2}{*}{$\begin{array}{l}\text { Prince- } \\
\text { White } \\
\text { (1957) }\end{array}$} \\
\hline & $\begin{array}{l}\text { No. of } \\
\text { Treatments } \\
\end{array}$ & $\begin{array}{l}\text { No. of 1st } \\
\text { Treatments }\end{array}$ & & & $\begin{array}{c}\text { Out- } \\
\text { patients }\end{array}$ & $\begin{array}{c}\text { In- } \\
\text { patients }\end{array}$ & $\begin{array}{c}\text { Out- } \\
\text { patients }\end{array}$ & $\begin{array}{c}\text { In- } \\
\text { patients }\end{array}$ & & & & \\
\hline $\begin{array}{l}\text { Muscular pain } \\
\text { No muscular pain }\end{array}$ & 237 & $\begin{array}{l}10 \\
37\end{array}$ & $\begin{array}{l}13 \\
34\end{array}$ & $\begin{array}{l}97 \\
77\end{array}$ & 21 & $\begin{array}{r}51 \\
1\end{array}$ & $\begin{array}{l}51 \\
39\end{array}$ & $\begin{array}{r}68 \\
221\end{array}$ & $\begin{array}{r}30 \\
119\end{array}$ & $\begin{array}{l}46 \\
79\end{array}$ & $\begin{array}{l}125 \\
104\end{array}$ & $\begin{array}{l}16 \\
34\end{array}$ \\
\hline
\end{tabular}


chloride. It seems clear that the incidence of such pains in patients receiving E.C.T. is lower than in reported series of patients not receiving this treatment and approximates to the incidence in patients who are kept in bed for 24 hours after receiving their anaesthetic. The incidence in relation to the number of anaesthetics given is much lower than that in any other series.

This finding appears to be a direct contradiction of the reports that the incidence of muscle pain is lowered by rest after the anaesthetic or by the reduction of the muscle activity consequent upon depolarization by the prior administration of nondepolarizing muscle relaxants. A direct relation between muscular pain and physical illness may be possible. If this were so, however, we should expect out-patients to be less physically ill than in-patients and therefore to have less pain. This has not been the case in those series where E.C.T. has not been given.

It may be possible to revive and modify Currie's (1953) original suggestion. He thought that the chest pain which his patients reported might be associated with overenthusiastic ventilation of the paralysed patient. The main difference between our patients and those in other series is the induction of a generalized fit, with muscle contractions which are visible despite the effect of the muscle relaxant. It may be possible to argue that the pains are related to the period of flaccidity which the patients undergo. This may have an effect related either to physical distortion of flaccid muscle or to some biochemical change related to this inactivity. For instance, metabolites may accumulate in inactive muscles which give rise to pain if the muscles are exercised immediately power returns. Such a mechanism may account for the differences between our series and the comparable out-patients series, and also for the previously observed differences between out-patients and in-patients.

\section{Summary and Conclusions}

The incidence of headaches and muscular pain arising after E.C.T. was investigated in 47 ambulant psychiatric patients who received a total of 259 treatments. Thirteen patients complained of muscular pain on a total of 22 occasions. Twenty-seven patients reported headaches on a total of 62 occasions. Headache was less common on the first treatment than on subsequent treatments.

The incidence of muscular pain in relation to the number of patients treated was significantly lower than in previous reports on out-patient series of patients who did not receive E.C.T. $(\mathbf{P}<0.001)$.

The incidence of muscular pain in relation to the number of anaesthetics given is lower than that in previously reported series of patients not receiving E.C.T. to a highly significant extent $(\mathrm{P}<0.0005)$.

We should like to thank Professor E. Stengel for arousing our interest in problems of pain in psychiatric patients, and our colleagues in the Department of Anaesthetics for their co-operation.

\section{REFERENCES}

Burtles, R., and Tunstall, M. E. (1961). Brit. F. Anaesth., 33, 24.

Churchill-Davidson, H. C. (1954). Brit. med. ¥., 1, 74.

Currie, T. T. (1953). Ibid., 1, 1032.

Engel, G. L. (1959). Amer. f. Med., 26, 899.

Foster, C. A. (1960). Brit. med. 7., $2,24$.

Hegarty, P. (1956). Brit. 尹. Anaesth., 28, 209.

Leatherdale, R. A. L., Mayhew, R. A. J., and Hayton-Williams, D. S. (1959). Brit. med. F., 1, 904.

Maxwell, A. E. (1961). Analysing Qualitative Data. Methuen, London.

Morris, D. D. B., and Dunn, C. H. (1957). Brit. med. Ұ., 1, 383.

Prince-White, F.'(1957). Ibid., 1, 761.

Szasz, T. S. (1957). Pain and Pleasure. Basic Books, New York.

Tewfik, G. I. (1963). Brit. med. 7., 2, 251.

\title{
Adherence of Bath Oil to Keratin
}

\author{
JOHN M. KNOX,* M.D.; RYOHEI OGURA,* M.D., PH.D.
}

Self-emulsifying oils are being used to treat patients with dermatological diseases in which the skin is abnormally dry. Formulations of this type were commercially introduced after it was demonstrated that mixing recently developed surfaceactive agents with an oil gave the oil self-emulsifying properties (Knox et al., 1956, 1958). Although several of these formulations are available their use has not been extensively studied.

Taylor $(1961,1963)$ reported that mineral-oil products adhere better to the skin than do vegetable-oil formulations and that oilated oatmeal preparations leave little residual oil on the skin. In his two studies the patient's arm or body was immersed and the loss of oil from the emulsion was considered to be the amount of oil adhering to skin. The quantity of oil absorbed seemed directly proportional to the concentration of oil in the emulsion. It increased with higher bath-water temperatures and with longer incubation times, up to 20 minutes. The skin of patients with atopy, psoriasis, neurodermatitis, and ichthyosis absorbed approximately $70 \%$ more oil than did normal skin. Clinical studies attesting to the therapeutic effectiveness of these

* From the Department of Dermatology, Baylor University College of Medicine, Houston, Texas. agents have been published by James $(1959,1961)$, Spoor (1958), and Lubowe (1960).

This is a report of a series of experiments performed to confirm and further delineate factors which influence the adherence of bath oil to keratin, and to establish a laboratory technique for evaluating these factors. These studies used normal keratin, defatted keratin, psoriasis scales, and defatted psoriatic scales.

\section{Materials and Methods}

Stratum corneum and psoriatic scale were pulverized in a Willy laboratory mill to make particles that could pass through a 40-mesh screen. In some experiments test material was defatted with ether in a Soxhlet reflex distillation apparatus.

Four commercially available bath oils and a variety of formulations prepared by our pharmacists were selected for study. Bath-oil formulations were emulsified with distilled water in the desired concentrations and distilled water was used as the control. The quantitative procedure employed to determine the amount of oil absorbed by keratin was as follows. 